\title{
Experimental Investigation of TIG Welded Additive Manufactured Inco-718 Sheets
}

\author{
Damodar Chalawadi ${ }^{a, b}$, Subramanian Palani Kumaresh Babu ${ }^{a}$, Veeman Dhinakaran ${ }^{c}$ (D) \\ ${ }^{a}$ National Institute of Technology, Department of Metallurgical Engineering, Tiruchchirappalli, Tamil \\ Nadu, India. \\ ${ }^{b}$ Gas Turbine Research Establishment (GTRE), Bengaluru, Karnataka, India. \\ ${ }^{c}$ Centre for Applied Research, Chennai Institute of Technology, Chennai, Tamil Nadu, India.
}

Received: February 24, 2020; Revised: April 19, 2020; Accepted: May 5, 2020

\begin{abstract}
In this research work, Inconel 718 specimens are fabricated by Direct Metal Laser Sintering process in the closed chamber which is filled with argon gas environment from a pre-alloyed powder. The process contains the high intensity of the laser source to melt the powder material, and the segment is placed on the top of the previous layer. Plates were vertically fabricated systematically (i.e., z-axis) and columnar grains are exhibited perpendicular to the build direction (i.e., x-axis). Test specimens are stress-relieved at $980^{\circ} \mathrm{C}$ for 2 hours and the recrystallized zone are found to be spheroid structure precipitates. The Ni-Cr matrix in the recrystallized interface and grain boundaries is observed in the samples, the micro hardness of the as-fabricated material is found as 340-350 VHN. Also, correspondingly mechanical properties are comparable with the wrought inco-718 alloy material. Further, the as build condition specimens are used for making butt joint configuration using Tungsten Inert Gas (TIG) welding process and Mechanical and microstructural properties are studied. The studies on welding of additive manufactured component will ensure the weldability of the AM material for the research community and industry.
\end{abstract}

Keywords: Additive manufacturing, Inconel 718, Direct Metal Laser Sintering, TIG welding.

\section{Introduction}

Technology is increasing in modern days rapidly. The researchers, scientists, and academians are working for the innovation of the world. This healthy competition among them leads to the development of new materials, new products, technology, and so on. Materials are developed to fulfil the desired quality and reliable for production such as alloys, super alloys, composites, and natural fibre. The new method of production of the materials is evolving for the smooth production of the materials. Various alloys with the different components are being created to replace the existing materials with enhanced behaviour. An example of such alloy is Ni-based alloy, found its wide range of application in the field of aerospace, and industrial purpose. Inconel 718 is an alloy of $\mathrm{Ni}-\mathrm{Cr}$ solid solution hardened austenite. It has been widely used for the production of the gas turbine engine components. The researchers have found that the usage of the Ni-based alloys has been increased drastically over the past few decades. It exhibits excellent mechanical behaviour and lightweight in nature. These great features of the Ni-based alloys make it fit for the application of the aerospace industry ${ }^{1}$. The word Inconel is the term used by International Nickel Company which contains high composition of a nickel and it is not naturally magnetic. It is an alloy with high strength, corrosion-resistant mainly composed of Ni-Cr material. The composition of the alloy is Ni 50-55, Cr17-21, Nb 4.55-5.50, Mo2.8-3, Mn$0.35 \mathrm{max}$ A10.2-0.80\%, etc. This alloy can be easily used

*e-mail: damugtre@gmail.com for the fabrication of the complicated parts. The wrought Inco-718 is being predominantly used in the wrought form. Wrought is a process that mechanically works a casted billet or ingot several times at high temperature to get the final product therefore, wrought microstructure is naturally more homogeneous and has finer grains than cast micro structure. The heat treatment is applicable by standard solution treatment which produces high rupture properties, tensile strength and fatigue strength. Kirman et al. had proposed that Inconel-718 usually shows three different intermetallic phases in its wrought form. They have also focussed on the application of the Inconel-718 in the specific fields like production of gas turbine blades, turbochargers rotors, and in aerospace industries. It is shown that the Inconel-718 is also used for structural application up to the temperature range of $700 \mathrm{C} .{ }^{2}$ Cline et al. ${ }^{3}$ had published a research work in the field of developing pre-alloyed powders by using a technique called rapid solidification. They concluded that theses powders are accessible for the creation of the actual alloys such as Ni-Cr alloys, Ni-Fe-Cr alloys, and $\mathrm{Ni3}-\mathrm{Nb}$ alloys.

The behaviour study of Inconel-718 had been proposed by Rao et al. ${ }^{4}$ in their research by changing the oxygen level. The tests were conducted at $140 \mathrm{ppm}, 180 \mathrm{ppm}$, and $275 \mathrm{ppm}$ level of oxygen and it was followed by Hot Isotactic Pressing (HIP) process. The tensile test of all the specimen were proceeded to predict mechanical characteristics such as ultimate strength and yield strength. It is concluded that the content of oxygen in the alloy had a direct relationship with the ductility of the alloy, but its ultimate strength remains 
the same for all level of oxygen content. Nandwana et al. had made a durability study on the Inconel-718 powder. The author inferred that the Inconel-718 powder could be used many times without any variation in its chemical property $^{5}$. The selective laser melting process is used for the fabrication of the Inconel-718 cylinders. The process is carried out in the presence of gas like either argon or nitrogen. The study revealed that the fabrication of the Inconel-718 cylinders exhibits an unusual columnar microstructure. It is concluded that there is not any variation in the mechanical characteristics of the Inconel-718 alloy components ${ }^{6}$.

The Inco-718 is difficult to weld due to formation of HAZ, microfussuring, and other features like element segregation grain size and secondary phase distribution inference microfussuring. These effects can be controlled by desired heat treatment ${ }^{7}$. In this paper, an effort has been taken to study the mechanical and microstructural behaviour of Inco-718 that are fabricated by using a technique called Direct Metal Laser sintering (DMLS). This process makes the utilization of inert gas (argon gas). The mechanical and microstructural behaviour of the Inco-718 is carried out by conducting optical Metallography and X-ray diffraction analysis ${ }^{8}$. The mechanical properties such as hardness and tensile strength are also measured for fabricated and heat-treated components. The additive manufactured products are used for direct end use application. The Inco-718 aero engine components such as stator, rotor blades, atomizers, swirler which are produced through additive manufacturing by this research work are used in aerospace applications.

\section{Experimentation: Additive Manufacturing}

Inconel 718 is chosen as the candidate material powder for this research work. 3D printing or Additive manufacturing is a methodology that uses three dimensional computer aided design (CAD) datasets to produce parts which are built layer upon layer with laser melting at power bed ${ }^{9,10}$. In order to build the parts through DMLS technique, CAD model is required. CATIA is used to create the $\mathrm{CAD}$ model. The $\mathrm{CAD}$ model input is taken as a STL format to ensure the overlap and missing triangles. The STL files define the model to be fabricated and slices the model into cross section for both part as well as supports. These are sliced into thin horizontal cross section as it represents the thickness of the layer. These layers are the tool path that drives the laser. The part position and orientation should be considered carefully for the parts realization which will have an impact on operational efficiency throughout build quality and time. The part building fully automated and the process may take up to several hours to build depending on the complex and volume of the components. A 200W high-powered laser melts powdered metal layer by layer to build up one or multiple designs layer. Parts are built in an enclosed inert gas (argon) chamber. DMLS uses powerful LASER to melt powdered materials for accurate density to realization the Inconel 718 materials. Ytterbium fiber laser is focused via dynamic mirrors selectively melts the cross section through a computer-determined scan path. The fine-tuned laser, powder and layer additive process combine to form a powerful design freedom triad. DMLS process offers similar properties that can be used in aerospace and also the 3D printed metal parts are similar to forged parts in terms of density and strength. The fabricated parts are roughly $99 \%$ dense before post-processing. After heat treatments, DMLS parts will greatly surpass the parts in terms of porosity. Metal prototyping is familiar for complex parts and widely used in the aerospace sector. The process of DMLS is shown in the Figure 1. The process consists of numerous parameters. The process parameters which are considered in this research for building the specimens are tabulated (Table 1) and which have been chosen carefully in order to get desired parts with mechanical properties and surface finish for end usable metal parts. Figure 2 shows the vertically built specimens.

The particle size distribution of powder affects its character and it is an internal quality control test methods. Hence mechanical sieve shakers have been used for sieve analysis. Before building the test samples powder analysis carried out. The flow analysis and particle size analysis were don with the ASTM-F3049-14, ASTM-B214-16 and
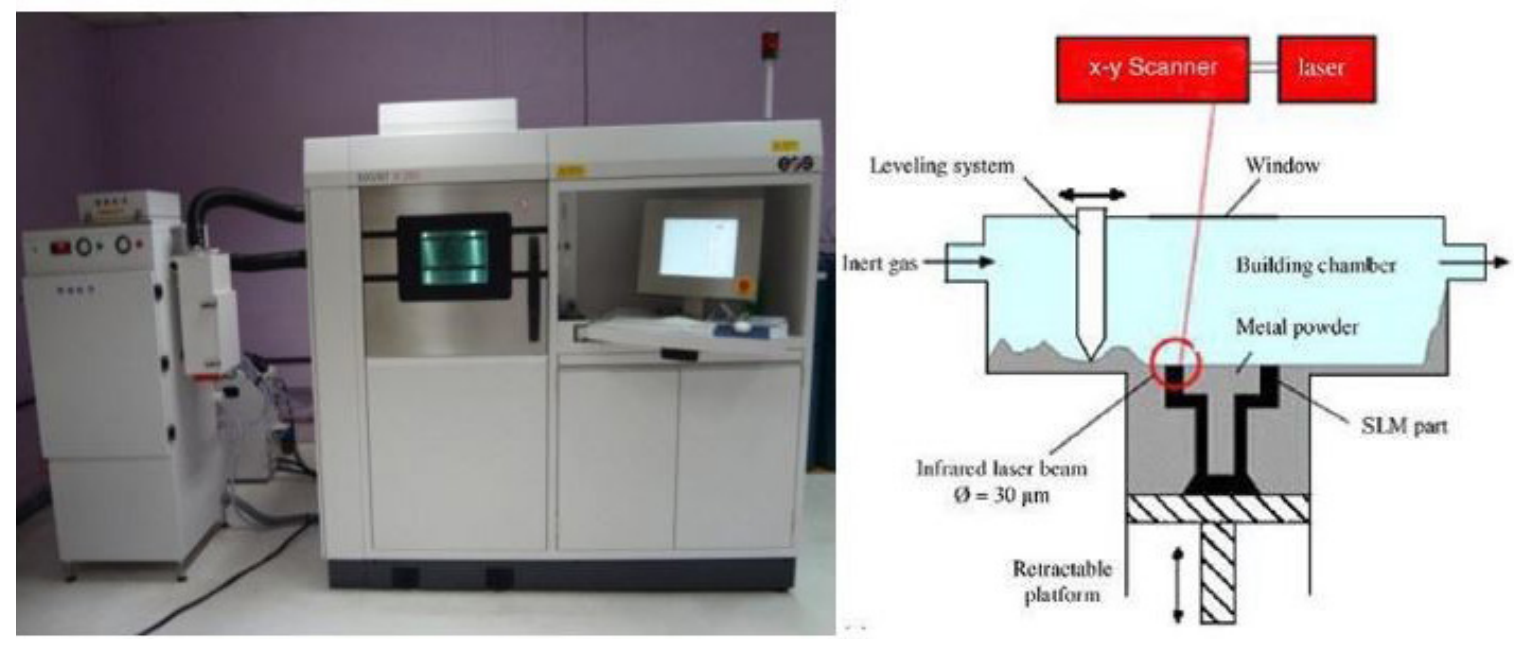

Figure 1. Direct Metal Laser Sintering M280 RP machine and building principle in schematic. 
ASTM-B214-15 for characterizing metal powder particles, Sieving method and sampling of metal power respectively.

The post processing is mandatory in Additive manufacturing which involves building stress relieving, removing of external supports and surface finishing. The surface finish of the build part will be $6 \mathrm{Ra}-8 \mathrm{Ra}$ which is not applicable for the application. Therefore, debarring, buffing and emery are required for good surface finish i.e. $2 \mathrm{Ra}$.

Inconel-718 is a heat and corrosion resistant nickel alloy. This material is ideal for many high temperature applications such as gas turbine parts, space and cryogenic applications. The chemical composition is analysed using $\mathrm{X}$-ray fluorescence (XRF) and the weight percentage of

Table 1. AM build Parameters.

\begin{tabular}{cc}
\hline Parameter & Value \\
\hline layer thickness & 20 microns \\
\hline scan speed & $7.0 \mathrm{~m} / \mathrm{s}$ \\
\hline powder particles & 20 microns \\
\hline build directions & vertical \\
\hline Laser power & $200 \mathrm{~W}$ \\
\hline platform pre-heat & $80^{\circ} \mathrm{C}$ \\
\hline part orientation & $15^{\circ} \mathrm{C} \mathrm{inclined} \mathrm{vertical}$ \\
\hline Recoater speed & $100 \mathrm{~mm} / \mathrm{s}$ \\
\hline
\end{tabular}

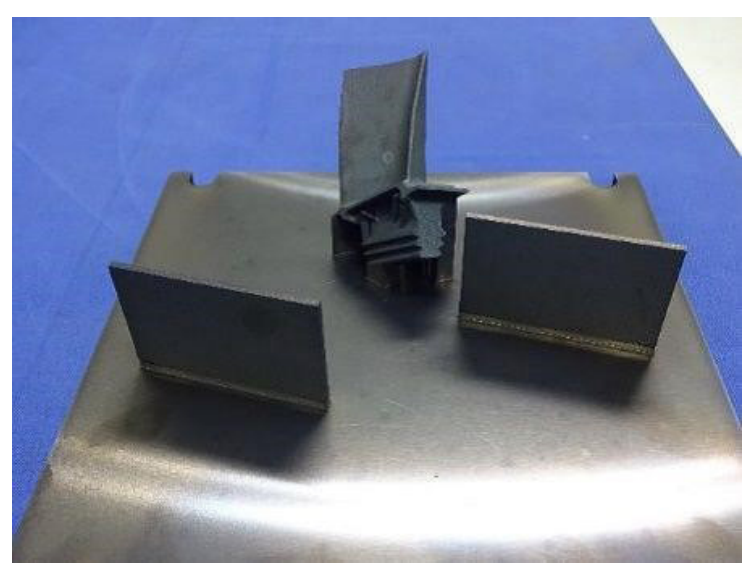

Figure 2. Samples of vertically built specimen in DMLS. the composition for built part and its comparison with the standard is given in the Table 2 .

\section{TIG Welding Experiment}

Atomised Inco-718 powders is experimentally used in DMLS to build the specimens of dimension $80 \times 100 \times 3 \mathrm{~mm}$ with proper orientation and Table 2 shows the chemical composition of Inco-718 powder.

The powdered particles used for the DMLS experiments were sized $40 \mu \mathrm{m}$ to $120 \mu \mathrm{m}$ with a medium value of 60 $\mu \mathrm{m}$. The thickness of the layer is set to $30 \mu \mathrm{m}$. The printed samples are post processed and joined with TIG welding. The two flatten specimens are prepered first for TIG welding make a ' $v$ ' grove. The papamters used for conducting welding trials were given in the Table 3 .

Also the influence of the microsructure is investigated by light microscopy with the magnification of 50X, for higher magnifications the scanning electron microscopy (SEM) equiped with Electro Back Scattered Diffraction (EBSD) detector is used for characterization of the microstructure.

\section{Results and Discussions}

Independent of external loads, there are internal stresses inside structures and materials which are called residual stresses. Residual stresses induce a strain which corresponds to changes in lattice spacing. Residual stresses are spontaneously in equilibrium as: Tensile residual stresses which are known as detrimental, compressive residual stresses which are known as beneficial and shear stresses. The Residual stress measurement is required for, manufacturing processes such as Sintering, machining operations, welding, shot peening, heat treatment and grinding generates residual stresses. It is very much essential to find the component withstand the necessary load conditions in its service life. Figure 3 represents the residual stress measurement set up and locations opted for the same. The values of residual stress measurement is tabulated in the Table 4.

Wire EDM process have been used to cut the specimen for tensile studies and microstructure analysis. The reason for using wire EDM process is to avoid the local heating of material since Ti-6AL-4V is having low thermal conductivity $(7 \mathrm{~W} / \mathrm{mK})$.

Table 2. Chemical Composition of Inco-718 by wt \%.

\begin{tabular}{lccccccccccc}
\hline & $\mathrm{Ni}$ & $\mathrm{Cr}$ & $\mathrm{Nb}$ & $\mathrm{Mo}$ & $\mathrm{Ti}$ & $\mathrm{Al}$ & $\mathrm{Co}$ & $\mathrm{Cu}$ & $\mathrm{C}$ & $\mathrm{Fe}$ \\
\hline Standard & $50-55$ & $17.0-21.0$ & $4.75-5.5$ & $2.8-3.3$ & $0.65-1.15$ & $0.20-0.80$ & $\mathrm{Max} 1.0$ & Max 0.3 & Max 0.08 & $19 \%$ \\
\hline Build Part & 51.48 & 19.58 & 5.15 & 3.89 & 0.97 & 0.87 & 0.37 & 0.18 & 0.015 & - \\
\hline
\end{tabular}

Table 3. TIG Welding Parameters.

\begin{tabular}{ccc}
\hline S1 No & Particulers & Usage Qnty/size \\
\hline 01 & Torch Argon & shield purging gas \\
\hline 02 & Gas purity & $99.9993 \%$ \\
\hline 03 & Polarity & DCSP(Direct current straight polarity) \\
\hline 04 & Weld Current & $50-55 \mathrm{Amps}$ \\
\hline 05 & Arc voltage / length & $10 \mathrm{volts} / 1.5-2.5 \mathrm{~mm}$ \\
\hline 06 & Filler wire / dia/feed /speed & inco $718 / 1.6 / 150 \mathrm{~mm} / 100 \mathrm{~mm} 100 \mathrm{~mm} / \mathrm{min}$ \\
\hline 07 & Tungsten electrode dia & $2.4 \varnothing$ \\
\hline 08 & Edge / root gap / face & $0.8 \mathrm{~mm} \mathrm{x} 45^{\circ} / 0.5 \mathrm{~mm} / 45^{\circ}$ \\
\hline
\end{tabular}




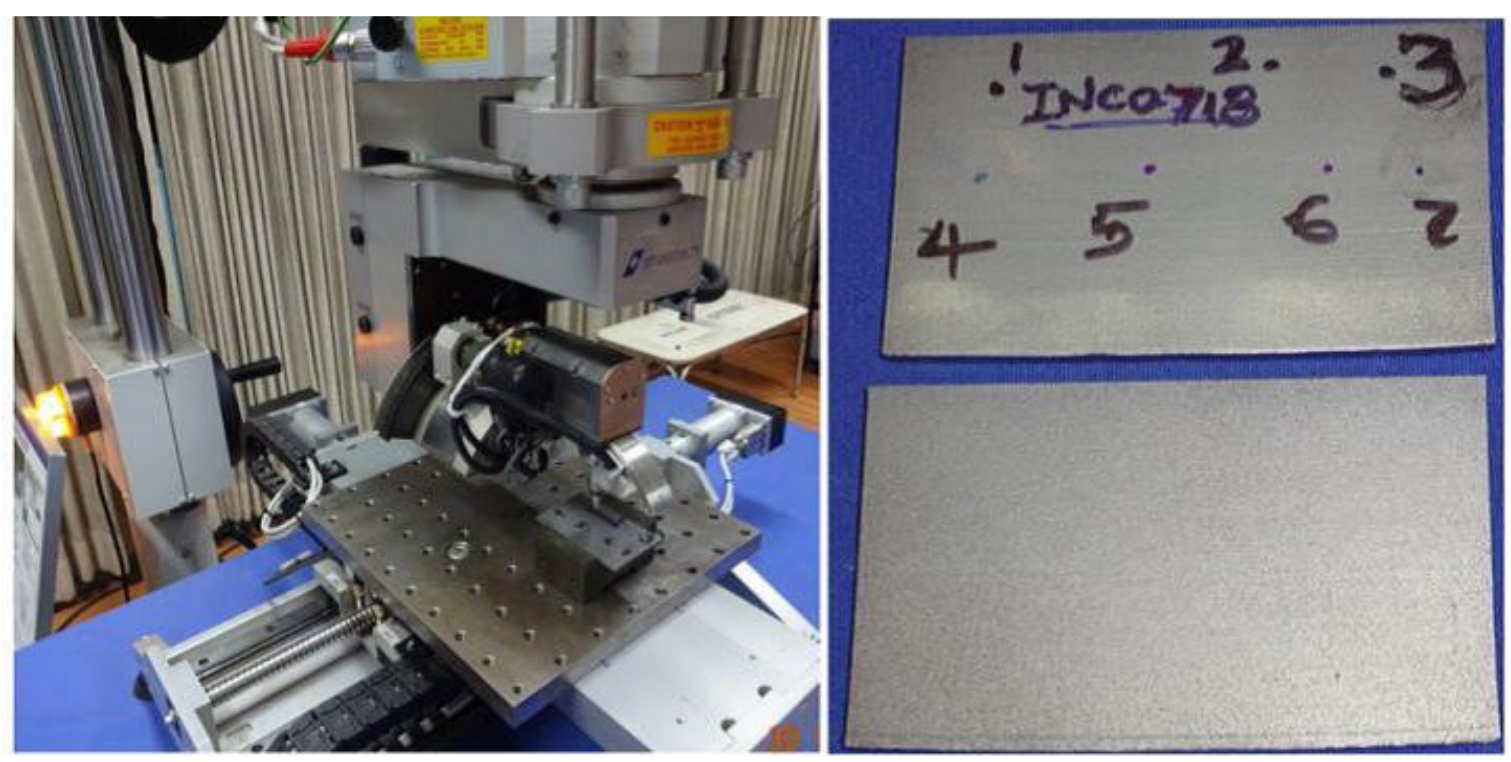

Figure 3. XRD Residual Stress Measurement.

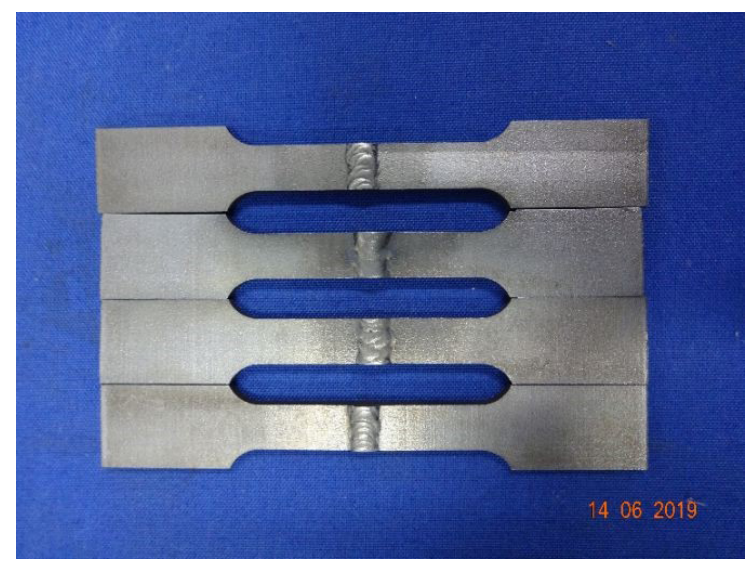

Figure 4. Tensile specimens.

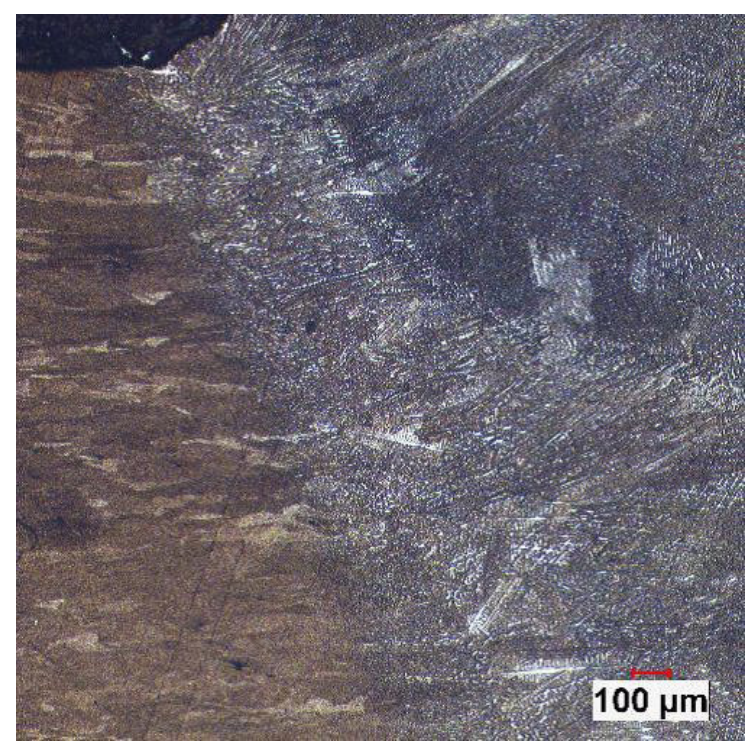

Figure 5. Microstructure of TIG welded specimen.
Table 4. Measurement of Residual stress at various locations.

\begin{tabular}{ccc}
\hline Location & $\begin{array}{c}\text { Additive Manufactured } \\
(\text { Stress value in MPa })\end{array}$ & $\begin{array}{c}\text { Wrought Material } \\
(\text { Stress value in MPa })\end{array}$ \\
\hline 1 & $-178.2 \pm 46.8$ & $-832.7 \pm 53.9$ \\
\hline 2 & $-139 \pm 54.6$ & $-893.5 \pm 23.9$ \\
\hline 3 & $-226.8 \pm 19.7$ & $-831.2 \pm 13.5$ \\
\hline 4 & $-188.3 \pm 27.9$ & $-355.0 \pm 51.1$ \\
\hline 5 & $-176.2 \pm 22.5$ & $-885.5 \pm 46.5$ \\
\hline
\end{tabular}

ASTM E08 standard has been used to conduct tensile testing. Figure 4 shows the tensile specimen prepared using wire EDM and Figure 5 shows the specimen used for metallurgical studies. It is observed from the Figure 5 that the coarse grains are present in the heat affected zone than the weld region. The boundaries are clearly visible to differentiate among heat affected zone, base material and weld zone.

Tensile test was carried out on wrought material, additive manufactured material of as-built condition and welded condition. The tensile test with the gauge length $25 \mathrm{~mm}$ is carried out at room temerature with UTM equiped with an extensometer. The following ultimate tensile strength was observed as shown in Table 5.

The ultimate tensile strength of the wrought material was found to be $998 \mathrm{MPa}$ and it is also inferred that there is no much more difference between the additive manufactured material and welded materials since both of them are with ultimate tensile strength of $940 \mathrm{MPa}$ and $935 \mathrm{MPa}$ respectively. The stress strain graph is shown in Figure 6.

XRD analysis has been carried out to understand the presence of different compounds in the welded zone and it is given in the Table 6. It is observed form the Figure 7 and Table 6 that Nickel, Iron and Chromium are the major constituents. These three constituents $(\mathrm{Ni}, \mathrm{Cr}, \mathrm{Fe})$ of the metal Inconel-718 represents the contribution towards the metal composition. It accounts for the large part of the experimental data set. Thus, Inconel's structural and chemical characteristics 




Figure 6. Stress Strain Graph.
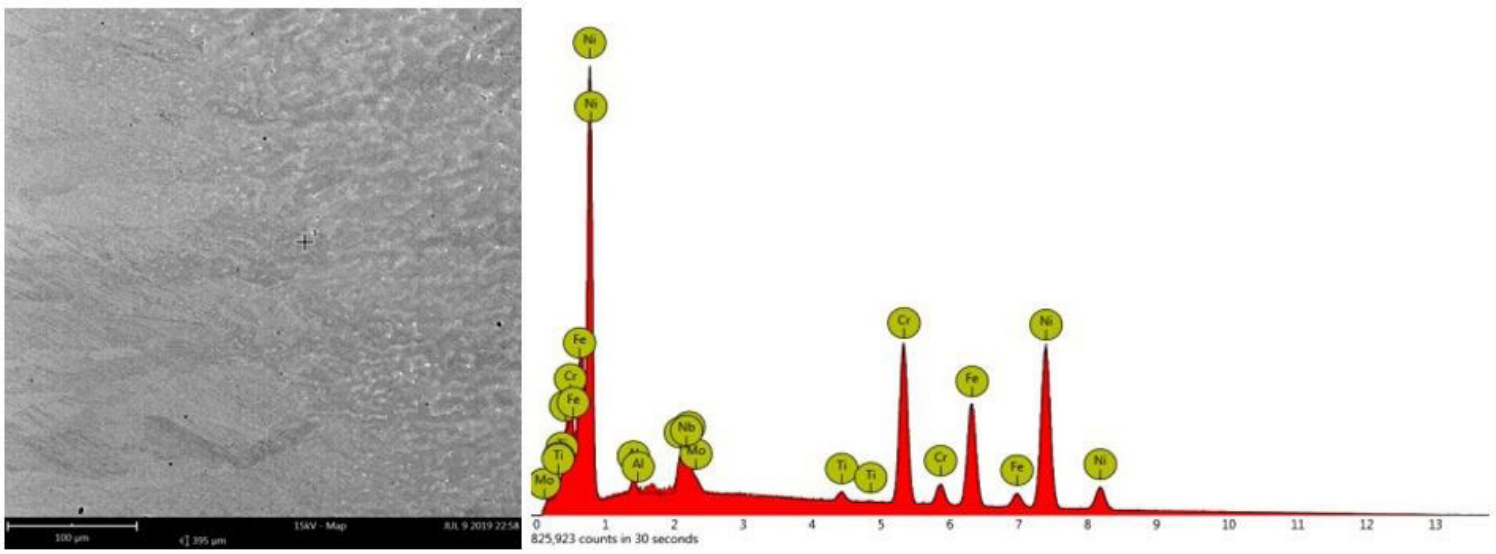

Figure 7. XRD Analysis (FOV: $395 \mu \mathrm{m}$, Mode: 15kV - Map, Detector: BSD Full).

Table 5. TIG Welding Parameters.

\begin{tabular}{cl}
\hline Wrought Ti-6Al-4V & $998 \mathrm{MPa}$ \\
\hline AM (as built condition) & $940 \mathrm{MPa}$ \\
\hline TIG welded specimen & $935 \mathrm{MPa}$ \\
\hline
\end{tabular}

Table 6. Elements in TIG welded Inconel 718 alloy.

\begin{tabular}{ccccc}
\hline $\begin{array}{c}\text { Element } \\
\text { Number }\end{array}$ & $\begin{array}{c}\text { Element } \\
\text { Symbol }\end{array}$ & $\begin{array}{c}\text { Element } \\
\text { Name }\end{array}$ & $\begin{array}{c}\text { Atomic } \\
\text { Conc. }\end{array}$ & $\begin{array}{c}\text { Weight } \\
\text { Conc. }\end{array}$ \\
\hline 28 & $\mathrm{Ni}$ & Nickel & 51.87 & 52.51 \\
\hline 26 & $\mathrm{Fe}$ & Iron & 19.84 & 19.11 \\
\hline 24 & $\mathrm{Cr}$ & Chromium & 20.78 & 18.64 \\
\hline 41 & $\mathrm{Nb}$ & Niobium & 2.72 & 4.35 \\
\hline 42 & $\mathrm{Mo}$ & Molybdenum & 2.39 & 3.95 \\
\hline 22 & $\mathrm{Ti}$ & Titanium & 0.90 & 0.75 \\
\hline 13 & $\mathrm{Al}$ & Aluminum & 1.51 & 0.70 \\
\hline
\end{tabular}

represent majority of these three metals. The X-ray peaks of Inconel 718 showed that the diffraction peak value is determined by its diffraction intensity. Higher scatter angle and lesser hydration ratio of these three metals are visible in the XRD analysis.

Microhardness measurement was also carried out on TIG welded specimen from the welding zone to the base

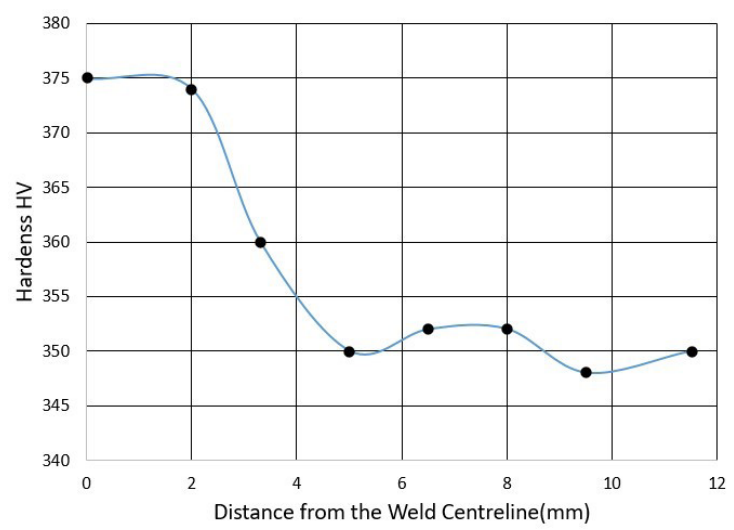

Figure 8. Distribution of microhardness.

metal. The distribution of microhardness is shown in the figure. It is understood form the Figure 8 that the hardness is high at the welding zone and gradually decreases towards the base metal. The hardness value is observed to $375 \mathrm{HV}$ at welding zone, $360 \mathrm{HV}$ at heat affected zone and 350 at the base metal. 


\section{Conclusions}

In this research work, Inconel 718 alloy was manufactured using DMLS additive manufacturing process. Butt joint specimen was made from the additive manufactured plate to investigate the mechanical and metallurgical properties of Additive manufactured TIG welded specimen. The following conclusions are drawn from the study.

1. The ultimate tensile strength of the wrought material was found to be $998 \mathrm{MPa}$ and it is also inferred that there is no much more difference between the additive manufactured material and welded materials since both of them are with ultimate tensile strength of $940 \mathrm{MPa}$ and $935 \mathrm{MPa}$ respectively. Hence, the ultimate tensile strength of TIG welded specimen is on bar with the additive manufactured one.

2. The microhardness value is observed to be $375 \mathrm{HV}$ at welding zone, $360 \mathrm{HV}$ at heat affected zone and $350 \mathrm{HV}$ at the base metal. The microhardness distribution is found to be high at the welding zone and gradually decreases towards the base metal. It is concluded that there is no difference of hardness value of welding of wrought material and additive manufactured materials.

3. It is inferred from the XRD that Nickel, Iron and Chromium are the major constituents.

4. The residual stress measurements show that additive manufactured sheet is with lesser stress values than wrought material. Hence, the additive manufactured Inconel 718 can be used for many applications compared to wrought material.

\section{References}

1. Patterson RJ, Cox AR, Van Reuth EC. Rapid solidification rate processing and application to turbine engine materials. JOM. 1980;32(9):34-9.

2. Sundararaman M, Mukhopadhyay P. Carbide precipitation in Inconel 718. High-Temp Mater Process. 1993;11(1-4):351-68.

3. Cline CF, Mehrabian R, Kear BH, Cohen M. Rapid solidification processing: principles and technologies. Baton Rouge: Claitor's Pubi. Div; 1978. p. 380.

4. Rao GA, Srinivas M, Sarma DS. Effect of oxygen content of powder on microstructure and mechanical properties of hot isostatically pressed superalloy Inconel 718. Mater Sci Eng A. 2006;435:84-99.

5. Nandwana P, Peter WH, Dehoff RR, Lowe LE, Kirka MM, Medina F, et al. Recyclability study on Inconel 718 and Ti-6Al$4 \mathrm{~V}$ powders for use in electron beam melting. Metall Mater Trans, B, Process Metall Mater Proc Sci. 2016;47(1):754-62.

6. Amato KN, Gaytan SM, Murr LE, Martinez E, Shindo PW, Hernandez J, et al. Microstructures and mechanical behavior of Inconel 718 fabricated by selective laser melting. Acta Mater. 2012;60(5):2229-39.

7. Gordine J. Some problems in welding Inconel 718. Weld J. 1971;50(11):480.

8. Arunkumar M, Dhinakaran V, Sivashanmugam N, Petley V. Effect of plasma arc welding on residual stress and distortion of thin titanium sheet. Mater Res. 2019;22(6):e20190366.

9. Shree M, Varsha V, Dhinakaran V, Rajkumar PM, Bupathi Ram $\mathrm{MD}$, Vijayakumar, et al. Effect of 3D printing on supply chain management. Materials Today: Proceedings. 2020;21:958-63.

10. Nagesha BK, Dhinakaran V, Varsha Shree M, Manoj Kumar KP, Chalawadi D, Sathish T. Review on characterization and impacts of the lattice structure in additive manufacturing. Materials Today: Proceedings. 2020;21:916-9. 